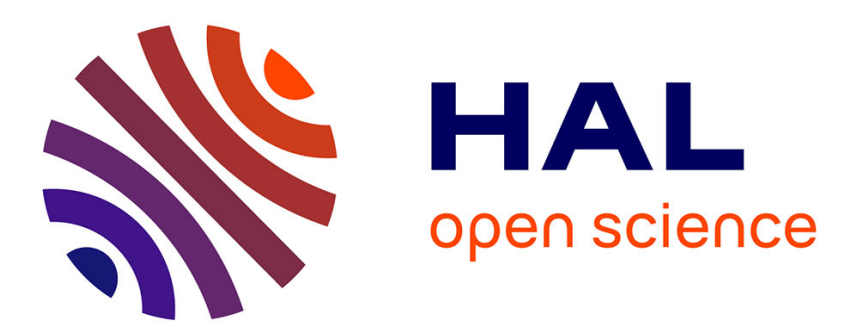

\title{
Single Atom Electron Emission from the Silicon Tip Coated by Calcium Fluoride with Samarium Dopant Ions
}

\author{
V. Konopsky, S. Sekatskii, V. Letokhov
}

\section{- To cite this version:}

V. Konopsky, S. Sekatskii, V. Letokhov. Single Atom Electron Emission from the Silicon Tip Coated by Calcium Fluoride with Samarium Dopant Ions. Journal de Physique IV Proceedings, 1996, 06 (C5), pp.C5-125-C5-128. 10.1051/jp4:1996520 . jpa-00254399

HAL Id: jpa-00254399

https://hal.science/jpa-00254399

Submitted on 1 Jan 1996

HAL is a multi-disciplinary open access archive for the deposit and dissemination of scientific research documents, whether they are published or not. The documents may come from teaching and research institutions in France or abroad, or from public or private research centers.
L'archive ouverte pluridisciplinaire $\mathbf{H A L}$, est destinée au dépôt et à la diffusion de documents scientifiques de niveau recherche, publiés ou non, émanant des établissements d'enseignement et de recherche français ou étrangers, des laboratoires publics ou privés. 


\title{
Single Atom Electron Emission from the Silicon Tip Coated by Calcium Fluoride with Samarium Dopant Ions
}

\author{
V.N. Konopsky, S.K. Sekatskii and V.S. Letokhov \\ Institute of Spectroscopy, 142092 Troitsk, Moscow Region, Russia
}

\begin{abstract}
We present the first experimental results of the studying of field electron emission from sharp silicon tips covered by thin dielectric $\mathrm{CaF}_{2}$ layers containing $\mathrm{Sm}$ dopant ions. Some indications on the resonant tunneling of electrons from sharp silicon tip through dopant samarium ions inside the coating have been observed, which can be regarded as an implementation of one-atom electron source of a new type, based on dielectric coating of emitting tip.
\end{abstract}

\section{INTRODUCTION}

As far as at 1968 Clark and Young have demonstrated the first "one-atom electron source" - namely, a material increase of field electron emission current from tungsten tip when single strontium atom arrives on its surface ([1], see a review of the first experiments in the field in [2]). Much lately Fink has succeeded in preparation of the "real" one-atom electron sources based on ultrasharp tungsten needles where emission current takes place through only a few, probably one, $W$ atom [3]. Interest to such sources has been strongly motivated by the rapid progress of the electron holography technique [4], where high quality "point-originated" electron beams are required. In a number of papers it was shown that local emission current can be increased by factors as large as $\sim 10^{2}-10^{4}$ when a single "quantum particle" such as atom, molecule or cluster is adsorbed on the emitting tip (see, for instant Refs. [5-8]; in Ref [8] it was even proposed to use such an effect for the information storage).

In this paper we consider another possibility of one-atom electron source based on sharp metal or semiconductor emissive tip covered by dielectric epitaxial layers containing dopant ions or defects. Such dopant ions or defects can possess a number of excited states lying in the forbidden zone of a dielectric and thus, resonant tunneling process through these states can materially enlarge the emission current in comparison with such a current for the case of pure (undoped and defectless) dielectric coating (see Fig. 1; note, that this picture of resonant tunneling process is more or less the same with the picture of resonant tunneling through adsorbed atoms or molecules [7] and an analogous consideration can be applied).

Dielectric coating of sharp field emitters are now intensively studied as a perspective method to improve the emissivity and emission stability of single emitters and emitter arrays, as it was shown, for instance, for diamond [9] and calcium fluoride [10] coating of silicon tips. Additional advantages of $\mathrm{CaF}_{2}$ coating on $\mathrm{Si}$ are its close to zero but negative electron affinity [11] and an excellent matching of its lattice 
constant with this of silicon which enables to obtain perfect $\mathrm{Si} / \mathrm{CaF}_{2}$ interfaces $[12,13]$. By these reasons realization of one-atom electron source based on emissive tip covered by an epitaxial layer seems especially perspective for us. Note also, that different dopant ions with the desirable concentration can be easily introduced into the $\mathrm{CaF}_{2}$ coating during the process of its grows. Rare earth dopant ions in calcium fluoride can be in both bi- or threevalent states, which also enlarges the possibilities for the resonant tunneling process in the case considered.
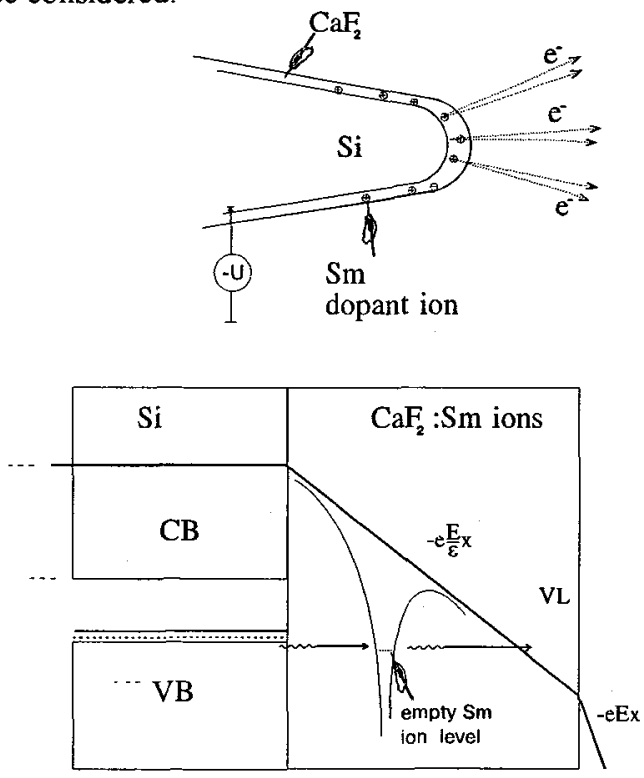

Fig.1. Illustrating the resonant tunneling process from $\mathrm{Si}$ tip through dopant $\mathrm{Sm}$ ion in $\mathrm{CaF}_{2}$ coating on the tip surface. VB, CB - valence and conductance bands of Si, VL - vacuum level.

\section{EXPERIMENTAL RESULTS AND DISCUSSION}

\subsection{Preparation of the tips}

High conductivity $n$-type single crystal Si whiskers were grown on one end of a Si rod with dimensions of $1 \times 1 \times 10 \mathrm{~mm}$. The growth end of the rod was polished and etched in an $\mathrm{HF}-\mathrm{HNO}_{3}$ solution. The dimensions of the face after pre-growth preparation were approximately $0.5 \times 0.5 \mathrm{~mm}$. As-grown whiskers were first sharpened by means of wet etching. Next, repeated thermal oxidation with HF etching for oxide removal was performed. Prepared tips were $100 \mu \mathrm{m}$ in height, and had a radius of curvature of less than $25 \mathrm{~nm}$. Further details of the Vapor-Liquid-Solid growth technique and sharpening procedure can be found in [14].

$\mathrm{CaF}_{2}$ films were grown on $\mathrm{Si}$ tips by molecular beam epitaxy (MBE) technique. Base pressure in the growth chamber was $0.510^{-11}$ Torr; $\mathrm{CaF}_{2}$ containing samarium in necessary concentration has been evaporated from a Knudsen cell. The temperature of Si sample during MBE-growth was estimated about $500-600^{\circ} \mathrm{C}$. The thickness of $\mathrm{CaF}_{2}: \mathrm{Sm}$ coating was $3 \mathrm{~nm}$, concentration of Sm dopant ions in the coating was $0.2 \mathrm{~mol}$. \%. Further details of $\mathrm{CaF}_{2}: \mathrm{Sm}^{2+}$ on $\mathrm{Si}$ growth process can be found in [13]. 


\subsection{Field emission images of the tips.}

The tip under study was placed in vacuum chamber of field electron (ion) emission microscope and constant voltage in the range $0-2.5 \mathrm{kV}$ was applied on it. The electrons emitted from the surface of the tip were registered by microchannel-plate-fluorescence-screen assembly placed at a distance of $R \cong 10 \mathrm{~cm}$ from the tip. The optical image formed at the exit from the assembly was picked up by a TV camera

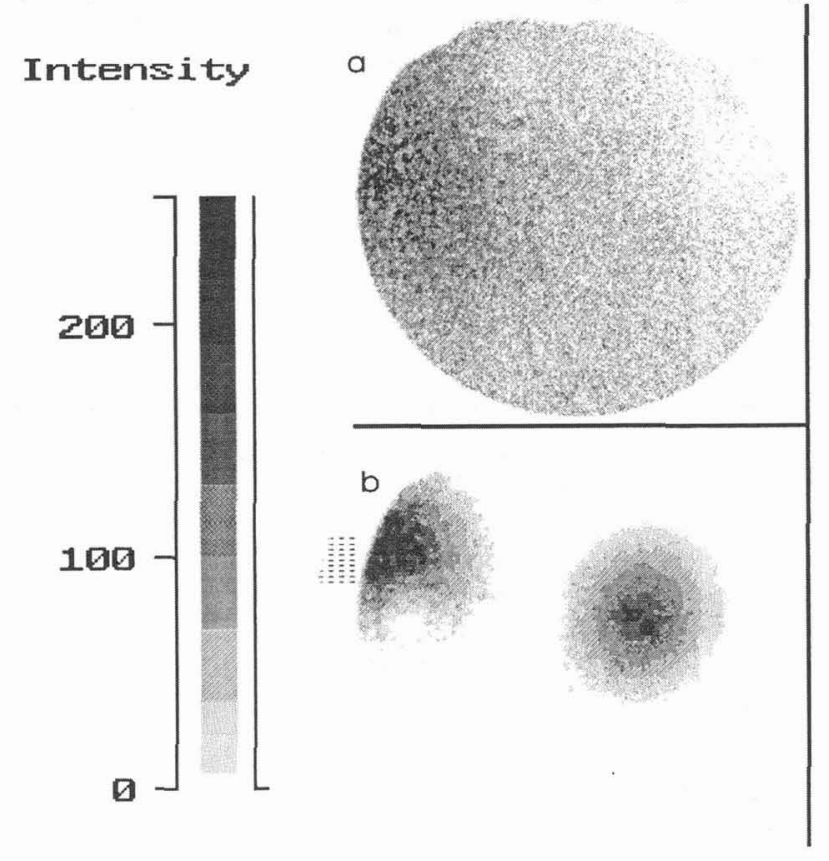

Fig.2. Field electron emission images of uncovered $\mathrm{Si}$ tip (a) and Si tip covered by $3 \mathrm{~nm}-$ thick $\mathrm{CaF}_{2}: \mathrm{Sm}$ epitaxial layer (b).

operated in conjunction with a Model Argus-50 image processing computer system (Hamamatsu Photonics $\mathrm{K}$. K., Japan). The diameter of the active region of the MCP is $32 \mathrm{~mm}$, so only a part of the tip $(\approx \mathrm{r} / 2 \times \mathrm{r} / 2$ area) can be imaged.

The field electron emission image of $\mathrm{Si} / \mathrm{CaF}_{2}: \mathrm{Sm}$ tip is presented on Fig. $2 \mathrm{~b}$. It consists of two bright emission spots the diameters of which correspond to expected resolution limit. Images analogous to this presented on Fig. $2 \mathrm{~b}$ and containing different distinct small-size spots were observed only for $\mathrm{Si} / \mathrm{CaF}_{2}: \mathrm{Sm}$ tips and were not observed for the case of uncovered sharp Si tips as well as for the case of sharp $\mathrm{Pt} / \mathrm{Ir}$ needles covered by pure undoped $\mathrm{CaF}_{2}$ layers. The typical emission image of uncovered $\mathrm{Si}$ tip is presented on Fig. 2a: no individual bright spots can be found here and one should say about more or less homogeneous emission.

In our opinion these images preliminary can be treated as a first indication of the experimental observation of single atom electron source due to the resonant tunneling of electrons through the energy states of a dopant ion in the dielectric coating. It is well known, that dopant rare earth ions in calcium fluoride possess a number of low- and middle energy electron states some of whose can be suitable for the resonance tunneling process. For instance, for the $\mathrm{Sm}^{2+}$ ion located inside calcium fluoride lattice first excited $d$ - zone of energy states of a valence electron lies $1.7-2.2 \mathrm{eV}$ higher than ground $f$-zone (and certainly there are a lot of higher excited states) [15]. If one will use for the tunneling barrier height for the $\mathrm{Si} / \mathrm{CaF}_{2}$ interface the value of $2.2 \mathrm{eV}$ (as it was reported in [16]) and proposes for the localization of 
ground state of $\mathrm{Sm}^{2+}$ ion relative to the bottom of $\mathrm{CaF}_{2}$ conduction band the value in the range $1.7-3.6$ $\mathrm{eV}$ [15] he will obtain the energy scheme similar to this presented on Fig.1. This means that resonant tunneling of electrons from $\mathrm{Si}$ through ground or low-lying excited states of $\mathrm{Sm}^{2+}$ dopant ion looks quite possible from the point of view of the positions of energy levels involved in the process, especially for the $p$-type silicon.

Certainly this explanation is of a rather preliminary character and additional experiments are necessary to understand the details of the resonant tunneling process. First of all it is necessary to explore the dependence of the high resolution electron emission images on the details of $\mathrm{CaF}_{2}: \mathrm{Sm}$ growth process and thus the possible importance of others than dopant ions imperfections on the $\mathrm{Si} / \mathrm{CaF}_{2}$ interface, which we plan to do in the future experiments. Nevertheless we believe that the experimental results presented here are sufficiently interested by themself as a first indication of one-atom electron source of a new type which based on emissive tip covered by dielectric layer.

\section{ACKNOWLEDGMENTS}

This work was supported by Russian Foundation for Fundamental Research and Department of Defense (USA). We thank Hamamatsu Photonics K.K. for lending us the necessary instrumentation, E. I. Givargizov and V. V. Zhirnov for supplying us with sharp Si emitters and N. S. Sokolov with J. C. Alvaretz for the preparation of $\mathrm{CaF}_{2}: \mathrm{Sm}$ coatings on the Si tips.

\section{REFERENCES}

[1] Clark H. E., Young R. D., Surf. Sci. 12 (1968) 385-390.

[2] Gadzuk J. W., Plummer E. W., Rev. Mod. Phys. 45 (1973) 487-495.

[3] Fink H. W., Phys. Scripta 38 (1988) 260-263.

[4] Tomomura A., Phys. Today 43 (1990) 22-28.

[5] Lin M.E., Andres R. P., Reifenberger R., Phys. Rev. Lett. 67 (1991) 477-480.

[6] Binh V. T., Purcell S. T., Garcia N., Duglioni J., Phys. Rev. Lett. 69 (1992) 2527-2530.

[7] Gadzuk J. W., Phys. Rev. B47 (1993) 12832-12839.

[8] McClelland G. M., Watanabe F., Appl. Phys. Lett. 67 (1995) 3200-3202.

[9] Givargizov E. I., Zhirnov V. V., Stepanova A. L., Plekhanov P. S., Kozlov R. I., Appl. Surf. Sci. 94/95 (1996) 117-122.

[10] Konopsky V. N., Zhirnov V. V., Sokolov N. S., Alvarez J. C., Givargizov E. I., Bormatova L. V., Letokhov V. S., Sekatskii S. K., Report presented at 43 Intern. Field Emission Symp., July 14-19, Moscow, Russia; submitted to J. de Physique.

[11] Quiniou B., Schwarz W., Wu Z., Osgood R. M., Yang Q., Phillips J. M., Appl. Phys. Lett. 60 (1992) 183-185.

[12] Schowalter F., Fathauer L., J. Vac. Sci. Technol. A 41 (1986) 1026-1032.

[13] Sokolov N. S., Alvarez J. C., Yakovlev N. L., Appl. Surf. Sci. 60/61 (1992) 421-425.

[14] Givargizov E. I., J. Vac. Sci. Technol. B 11 (1993) 449-453

[15] Pedrini C., Rogemond F., McClure D. S., J. Appl. Phys. 59 (1986) 1196-1201.

[16] Rieger D., Himpsel F.L., Karlsson U.O., McFeely F. R., Morar J. F., Yarmoff J. A., Phys. Rev. B., 34 (1986) 7295-7306. 